\title{
A!
}

This is an electronic reprint of the original article.

This reprint may differ from the original in pagination and typographic detail.

Sundaria, Ravi; Nair, Devi Geetha; Lehikoinen, Antti; Arkkio, Antero; Belahcen, Anouar

\section{Effect of Laser Cutting on Core Losses in Electrical Machines - Measurements and Modeling}

Published in:

IEEE Transactions on Industrial Electronics

DOI:

10.1109/TIE.2019.2942564

Published: 01/09/2020

Document Version

Peer reviewed version

Please cite the original version:

Sundaria, R., Nair, D. G., Lehikoinen, A., Arkkio, A., \& Belahcen, A. (2020). Effect of Laser Cutting on Core Losses in Electrical Machines - Measurements and Modeling. IEEE Transactions on Industrial Electronics, 67(9), 7354-7363. [8848857]. https://doi.org/10.1109/TIE.2019.2942564

This material is protected by copyright and other intellectual property rights, and duplication or sale of all or part of any of the repository collections is not permitted, except that material may be duplicated by you for your research use or educational purposes in electronic or print form. You must obtain permission for any other use. Electronic or print copies may not be offered, whether for sale or otherwise to anyone who is not an authorised user. 
(C) 2020 IEEE. This is the author's version of an article that has been published by IEEE. Personal use of this material is permitted. Permission from IEEE must be obtained for all other uses, in any current or future media, including reprinting/republishing this material for advertising or promotional purposes, creating new collective works, for resale or redistribution to servers or lists, or reuse of any copyrighted component of this work in other works. 


\title{
Effect of Laser Cutting on Core Losses in Electrical Machines - Measurements and Modeling
}

\author{
Ravi Sundaria, Devi Geetha Nair, Antti Lehikoinen, Antero Arkkio, Anouar Belahcen, Senior member, IEEE
}

\begin{abstract}
Cutting of the electrical steel sheets to appropriate shape and size is performed during the manufacturing of electrical machines which leads to the magnetic material deterioration near the cutting edge. Epstein frame measurements of electrical steel samples of different widths cut by laser cutting are carried out in the range of $20 \mathrm{~Hz}$ to $400 \mathrm{~Hz}$ frequency of sinusoidal excitations. Two stators one with laser cut and another one with electric discharge wire cutting were manufactured and the effect of cutting on core losses was analyzed. The effect of cutting on the magnetic permeability and core losses are modeled with analytical equations. Furthermore, the model is implemented in the finite element simulation of the Epstein frame test setup. The presented loss model is found to reproduce the measurement results reasonably. The loss model is then applied to the simulation of a cage induction machine with time-stepping finite element analysis. A significant increase in core losses was observed both in simulations and measurements due to the effect of laser cutting. The presented cutting model closely follows the measured core losses.
\end{abstract}

Index Terms-Core loss, cutting, cut edge, electrical machines, finite element modeling, steel cutting, steel laminations.

\section{INTRODUCTION}

$\mathbf{M}$ ANUFACTURING of electrical machines, in general, involves cutting of electrical steel sheets to appropriate sizes, interconnecting steel sheets (welding, glueing, interlocking, etc.) to form stack and shrink fitting. Each of these manufacturing steps have an impact on losses in the final manufactured machine [1], [2]. Among these manufacturing effects, those related to the cutting of sheets have garnered the interest of the research community in the last couple of decades. Electrical sheets are typically cut by punching or laser cutting, which have a significant impact on the magnetic properties of iron. Researchers have measured its magnetic properties with the help of standard Epstein frame

Manuscript received Month Xx, 2019; revised Month Xx, 2019; accepted Month $x, 2019$. This research work has received funding from the European Research Council under the European Unions Seventh Framework Programme (FP7/2007-2013) / ERC Grant Agreement n. 339380.

R. Sundaria, D. G. Nair, A. Lehikoinen, A. Arkkio and A. Belahcen are with Department of Electrical Engineering and Automation, Aalto University, Espoo, 15500, Finland (e-mail: ravi.sundaria@aalto.fi). and single sheet tester. The generated plastic, residual and thermal stresses have been reported to translate into a drop in permeability and an increase in core loss density [1]-[5]. Furthermore, [6] and [7] investigated the effect of cutting on the optimal design of the electrical machines.

Based on the measurements on electrical steel samples, various researchers have proposed loss models that include the effect of cutting in the electrical machine simulation models [8]. [9] and [10] proposed building factors to include the effect of cutting in the core losses. Others such as [11] and [12] proposed a separate uniform degradation region near the cut edge to account for cutting effect. The continuous loss models have also been studied widely which takes into account the distance from the cut-edge [7], [13]-[17].

The mechanical cutting phenomenon is widely modeled by analytical functions which predict a gradual increase in flux density from cut-edge to middle of the lamination either by exponential functions [7], [13], [15] or polynomial function [14]. The measurements of laser cut steel samples are presented in [3], [18], [19]. To model the laser cutting effect [11] derives a uniform degradation layer near the cut-edge while [17] applies the same polynomial function based loss model developed for the mechanical cutting [14]. Irrespective of the cutting effect it is widely known that there will be higher degradation near the cut-edges. The analytical functions-based continuous loss models have the benefit of computational efficiency in finite element (FE) simulations with the help of higher or mixed order elements as shown in [20] and [21]. Therefore, this paper will modify the analytical function based continuous loss model [13] which is then applied with higher order elements. A simple analytical expression to include the cutting effect in hysteresis and excess loss coefficients is presented. The accuracy of the presented loss model is proved with the Epstein frame measurements as well as the measurements of machine prototypes.

As presented in the above literature; there has been extensive research on quantifying the effect of cutting with the help of magnetic measurements on electrical steel sheets. However, relatively fewer efforts have been made to quantify the effect of cutting in the full machine. This is because of challenges in validating the machine's simulated core losses with measurements. There are significant challenges in modeling of the rotational core losses, the effect of stresses caused by shrink fitting, interlaminar short circuits, welding effect, and possible 
local eddy currents etc. Each of these physical phenomena affects the core losses. Typically at the modeling stage, most of such effects are ignored which will make it difficult to compare the simulated and measured results especially in case of cutting where the difference due to cutting may be as low as $5-10 \%$ in the measured core losses. Therefore for reliable experimental measurement, we should have two identical machine prototypes which only differ with respect to the cutting method. Such an approach is followed in this paper.

[22] and [17] include measurement results from single machine prototype cut by mechanical cutting and laser cutting respectively. [13] compares two permanent magnet synchronous machines which are cut by wire cutting and shear. However, the focus was on the electromotive force measurement and the core losses were not measured. [16] studies the effect of laser cutting on the performance of permanent magnet assisted synchronous reluctance machines; here also the effect of cutting was considered only on the magnetic permeability and other performance parameters such as torque and direct and quadrature axis inductances. A loss model for the cutting effect on the core losses and the respective measurements are missing. [10] presents the magnetic measurements of stator laminations with and without heat treatment. As heat treatment is known to reduce the stress effect and the measured difference will partially show the effect of cutting. The ring core measurements were performed in [10]; therefore, the cutting effect in the stator teeth area which is one of the most affected parts is missing. Similarly, only ring core measurement with laser cut stator laminations are presented in [11]. Although, two identical prototypes which only differ in the cutting technique i.e. electron discharge machining (EDM) cut and laser cut were measured in [9], no loss segregation was given. The effect of cutting was considered as an additional factor in the total core loss which will make it difficult to scale the model to different machine geometries and operational frequencies.

This paper focuses on a reliable quantification of the effect of cutting on the core losses. The Epstein frame test was performed on the laser cut steel samples. From measurements, then a loss model was developed, as done in [13]. Further, the presented loss model is applied in finite element analysis (FEA) of the Epstein frame test setup and simulation results are compared with the measurements. Finally, the cutting effect was analyzed with core loss measurements in two different stators. The presented research work is an extension of the conference paper [23]. The novelty of the paper comes from the following points

1) A new modified loss model and validation

2) Comparative analysis of measured and simulated core losses of EDM cut and laser cut stators to analyze the cutting effect on the full machine.

This paper is divided into four sections. The current section provides the background, aim, and novelty of this research work. The following section describes the procedure of the Epstein frame measurements, the cutting loss model and finite element model. The corresponding results are presented in the

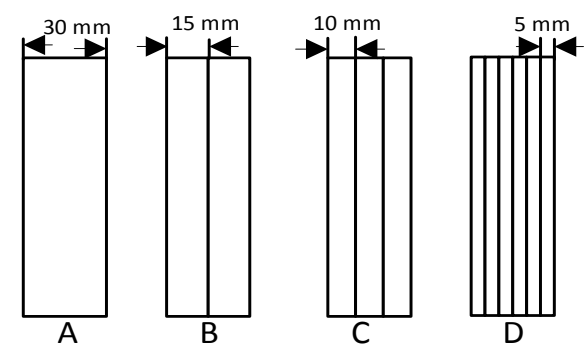

Fig. 1: Assembly of different width samples for magnetic measurements. Sample E is assembled in similar manner.

TABLE I: Test samples

\begin{tabular}{|c|l|l|}
\hline Sample & \multicolumn{1}{|c|}{ Detail } & $\begin{array}{l}\text { Total width } \\
(\mathbf{m m})\end{array}$ \\
\hline A & One sample of 30 mm & $1 \times 30=30$ \\
\hline B & Two 15 mm samples joined together & $2 \times 15=30$ \\
\hline C & Three 10 mm samples joined together & $3 \times 10=30$ \\
\hline D & Six 5 mm samples joined together & $6 \times 5=30$ \\
\hline E & Ten 3 mm samples joined together & $10 \times 3=30$ \\
\hline
\end{tabular}

respective subsections of the results section. Finally, the key findings of the research work are summarised in the conclusion and discussion section.

\section{METHOD}

This section is divided into five subsections: the first subsection deals with the magnetic measurements of the laser cut samples of different widths with the standard Epstein frame test setup. The second subsection describes the proposed loss model while the subsequent subsection describes the FEA model of the simplified Epstein frame test setup. The last two subsections present a time-stepping finite element model with higher order elements to efficiently model the cutting effect and a stator core loss measurement setup with unsloted rotor.

\section{A. Epstein frame measurements}

Magnetic measurements are usually performed on electrical steel samples with Epstein frame or single sheet testers in the industry as well as academia. As presented in the literature, many researchers have studied the effect of cutting by studying electrical steel samples of different widths. Following the same lines, this paper presents the results of five different types of samples having the same total material mass. The nonoriented electrical steel sheets of grade M400-50A having the lamination thickness of $0.5 \mathrm{~mm}$ are investigated in this paper. The assembly of samples of different widths is also shown in Fig. 1. The samples are cut by solid state continuous wave 400 W fiber laser Trumpf Trulaser Cell 3010 with $250 \mu \mathrm{m}$ beam diameter at the cutting speed of $11 \mathrm{~m} / \mathrm{min}$ [24]. The details of the measured samples are presented in Table I.

The magnetic measurements are performed with standard Epstein frame setup "MPG 100 D" by Brockhaus Measurements following the standard IEC: 604004-2 [25]. The 
magnetic test is having 16 strips, each of width $30 \mathrm{~mm}$ and joined by double tapped joints at the corners. The conducting edges are insulated by thin tape while assembling samples B, $\mathrm{C}, \mathrm{D}$, and E. The supply voltage was controlled to provide sinusoidal magnetic flux density. The electrical steel samples were demagnetized before the measurements and air flux compensation was considered with the help of the mutual inductor in the test setup.

\section{B. Loss model}

To account for the cutting effect, the following analytical expression is presented. The presented loss model is based on [13] with the modifications listed at the end of this subsection.

1) Effect on permeability: The effect of cutting on the magnetic permeability is mainly dependent on two parameters: the magnetic field strength $(H)$ and width of the sample. Local magnetic flux density was analyzed with experiments of mechanical cut samples of four different materials and an exponential function was fitted to reproduce the measured results in [15]. [26] showed that an exponential function for both $\mathrm{CO} 2$ laser cut and mechanical cut samples provided satisfactory results irrespective of cutting technique. Further, [18] studied the magnetic domain structure and domain wall movement by the magneto-optical Kerr effect (MOKE) to determine the local magnetic properties in terms of magnetic contrast. The local magnetic contrast shows similar results for mechanical cut and laser cut samples especially for lower field strength where the cutting effect is prominent. Analytical functions-based continuous loss model was proved computationally efficient in FE modeling of the cutting effect in [20], [21] where an exponential function is applied. Therefore, this paper applies exponential function for modeling the cutting effect.

Based on Ampere's law the measured magnetic field strength $(H)$ is considered constant across the measured sample. The local magnetic permeability $\mu(H, x)$ is presented in (1). Here $\Delta \mu(H)$ and $a$ are fitting parameters, therefore, $n$ number of data points will result in $n+1$ fitting parameters. $\mu_{n d}(H)$ is the magnetic permeability of non-degraded material and the distance from cut-edge is $x$. It should be noted that we will obtain the average measured permeability $\left(\tilde{\mu_{m}}\right)$ from magnetic measurements and corresponding average calculated permeability $\left(\tilde{\mu_{c}}\right)$ can be determined from (2) for a sample of lamination width $w$.

$$
\begin{gathered}
\mu(H, x)=\mu_{\mathrm{nd}}(H)-\Delta \mu(H) e^{-a x} \\
\tilde{\mu}_{c}(H, w)=\frac{2}{w} \int_{0}^{w / 2} \mu(H, x) d x
\end{gathered}
$$

2) Effect on core losses: Similar to the permeability of the measured material, it is also quite clear that core losses are affected by the cutting. [18] performed the conductivity measurements on the strips cut by different cutting techniques including laser and showed that conductivity is unaffected by the cutting process. Therefore, this paper will modify the hysteresis loss and excess loss coefficients for modeling the cutting effect and eddy current loss coefficient will remain unaffected. On the other hand, the eddy current losses will be mildly affected due to change in permeability due the cutting effect; this effect is ignored at low frequencies $(<400$ $\mathrm{Hz}$ ). As the hysteresis and excess loss depends on the local grain properties and domain wall movement, the effect of cutting is modeled in a similar fashion as local permeability i.e. considering the effect of magnetic flux density and an exponential function for distance from the cutting edge on the loss coefficients.

The three component core loss formula (3) was selected to improve the overall fitting of the cut-edge loss model [27]. The parameters such as coefficients of eddy current $K_{e}$ and exponent $\alpha$ are fixed at non-degraded value. The effect of cutting is then included in the hysteresis loss coefficient $K_{h}(B, x)$ and excess loss coefficient $K_{e x}(B, x)$. As we get the average hysteresis and excess loss coefficients $\tilde{K_{h m}}(B, w)$ and $\tilde{K_{\text {exm }}}(B, w)$ from measurements, (4) and (5) were averaged along $w$ to obtain the corresponding calculated average hysteresis and excess loss coefficients $\tilde{K_{h c}}(B, w)$ and $\tilde{K_{\text {exc }}}(B, w)$.

$$
\begin{aligned}
P(B, x) & =\sum_{n=1}^{n=N} K_{h}(B, x) B^{\alpha(B)} f_{n}+K_{e} B^{2} f_{n}^{2} \\
& \left.+K_{e x} B, x\right) B^{1.5} f_{n}^{1.5} \\
K_{h}(B, x) & =K_{h 0}+\Delta K_{h}(B) e^{-b x} \\
K_{e x}(B, x) & =K_{e x 0}+\Delta K_{e x}(B) e^{-c x} \\
\Delta K_{h}(B) & =b_{1} B^{3}+b_{2} B^{2}+b_{3} B+b_{4} \\
\Delta K_{e x}(B) & =c_{1} B^{3}+c_{2} B^{2}+c_{3} B+c_{4} \\
\tilde{K_{h c}}(B, w) & =\frac{2}{w} \int_{0}^{w / 2} K_{h}(B, x) d x \\
\tilde{K_{e x c}}(B, w) & =\frac{2}{w} \int_{0}^{w / 2} K_{e x}(B, x) d x
\end{aligned}
$$

The non-degraded permeability $\mu_{n d}(H)$ in (1) and parameters $K_{h 0}, \alpha, K_{e}$, and $K_{e x 0}$ are obtained by magnetic measurement of standard Epstein frame laser cut sample of width $30 \mathrm{~mm}$ (sample A). This paper ignores the effect of cutting on the widest sample i.e. sample A while deriving the non-degraded parameters. Ideally, sample A should be either heat treated or cut with EDM cutting to partially eliminate the effect of cutting. Following modifications have been done in the loss model [13] as part of the improvement.

1) The fitting parameter $a$ is made independent of field strength $\mathrm{H}$. The modification helps in easier generation of the local BH curves with monotonicity. The monotonicity is needed for better convergence of the Newton Raphson method applied to deal with the non-linearity in FE simulations.

2) A three-component core formula [27] was adopted to improve the numerical fitting.

3) Fitting parameter $\Delta K_{h}(B)$ is a cubic polynomial of magnetic flux density instead of a linear polynomial and parameter $b$ is independent of $B$.

The procedure to derive the fitting parameters is summarized as a flowchart in Fig. 2. 


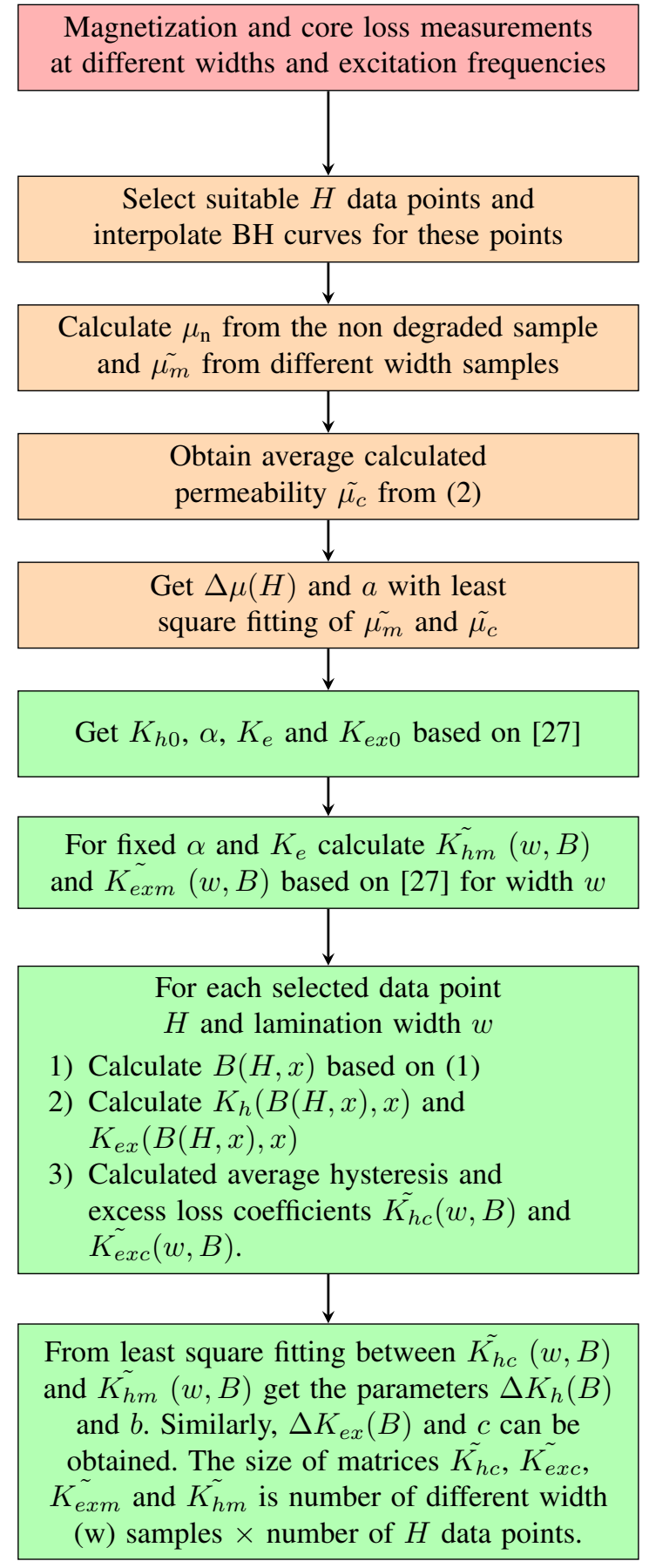

Fig. 2: Flowchart of the loss model

\section{FEA model of Epstein frame test setup}

The presented loss model can be verified against the finite element simulation of a simplified Epstein frame measurement system and the measurement results. We obtain single value curve in term of the peak value of magnetic flux density and the peak value of field strength along with core loss density as $\mathrm{W} / \mathrm{kg}$ from the measurements. Magnetic vector potential based formulation $(A V)$ can be used to solve the magnetic field distribution along the width of the lamination. To avoid the complexities arising from modeling air flux compensation in the Epstein frame, the measured magnetic

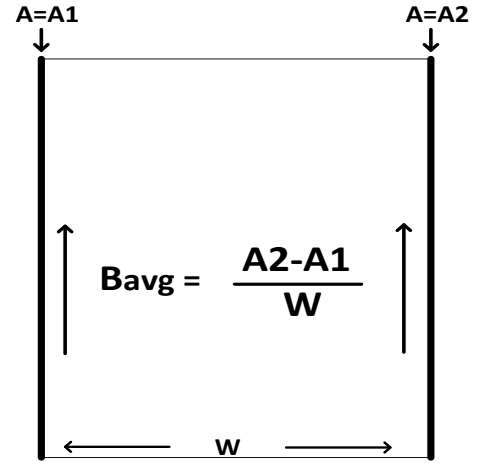

Fig. 3: Enforcement of average flux density by boundary conditions. Dirichlet boundary conditions are imposed on the bold boundaries.

flux is enforced in a rectangular steel sample. Hence, the primary and secondary coils of the Epstein frame test setup are not included in the FE simulations. The magnetic flux can be enforced with the help of a highly dense mesh and Dirichlet boundary condition as presented in Fig. 3. The resultant system of equations is presented in (10) and (11). Here $\mathbf{S}, \mathbf{f}$, and $\mathbf{A}$ are stiffness matrix, source vector and magnetic vector potential respectively. As there is no current source in the model, $\mathbf{f}$ can be replaced with a zero vector. Finally the simplified equation (11) can be solved to determine the vector potential $\left(\mathbf{A}_{n}\right)$ at the non Dirichlet nodes of the mesh. The subscript $n$ represents the non Dirichlet nodes whereas $d$ represents the Dirichlet nodes.

$$
\begin{gathered}
\mathbf{S A}=\mathbf{f} \\
\mathbf{S}_{n, n} \mathbf{A}_{n}+\mathbf{S}_{n, d} \mathbf{A}_{d}=0
\end{gathered}
$$

\section{Time-stepping FE simulation}

The time-stepping FE analysis of a cage induction machine and presented mock-up machine test setup is based on the voltage source model presented in [28]. The effect of end winding inductances and rotor bar resistances (in case of induction motor) are taken into account with the help of circuit equations. The effect of welding on the stator core and conductivity in steel laminations is ignored in FE simulations. Finite element formulation based on well known $A V$ formulation is written in MATLAB environment. The rotation of the rotor is modeled by remeshing air-gap elements at each timestep. Furthermore, to study the effect of cutting in the finite element simulation, higher order finite element formulation is adopted, which has not only proved to be computationally efficient [21] but also eliminate the need to make narrow geometric regions in machine geometry to model the cutting effect. As this is a recently published work, hence, in-house MATLAB based solver is used instead of commercial FE solvers. As presented by the authors earlier in the case of time-harmonic analysis, the effect of cutting is included in the stiffness matrix $S$ in this time-stepping simulation. The entries of the stiffness matrix $S_{i j}$ can be represented in terms of the reluctivity $\nu$ and the nodal shape functions $\phi$ in the domain $\Omega$. The effect of cutting in terms of the degradation of permeability from (1) is 
presented in the form of the cut distance dependent reluctivity $\nu(A, x)$.

$$
S_{i j}=\int_{\Omega} \nu(A, x) \nabla \phi_{i} \cdot \nabla \phi_{j} d \Omega
$$

\section{E. Mock-up machine test set-up for stator core loss mea- surement}

Two stators and one laminated rotor were manufactured. The geometrical dimensions of stators and rotor are the same as presented in Table V. The laminated rotor is manufactured without any bars or slots for bars. This test setup for the measurement of core losses is termed as "mock-up machine" in this paper. One of the stators was manufactured with the laser cutting while the second one was with the EDM cutting. EDM cutting is known to produce lesser stress and deliver a comparatively better quality of cutting [9], [13], [14].

The measured difference between the core losses of the two stators should reflect the effect of cutting. Following steps were taken to ensure the accuracy of the measurements to quantify the cutting effect in the core losses.

1) Other than the cutting method all other manufacturing parameters are identical. Both the stators are manufactured from electrical steel from the same mother coil to avoid variation in the electrical steel manufacturing. Both have identical winding, welding technique and number of weld spots to stack the stators. Both the stators are laser welded with 13 welding spots each by Trumpf Trulaser Cell 3010 [24].

2) As the focus of the measurement was core losses; blocked rotor test was performed to avoid inclusion of the friction losses in the total measured losses.

3) The applied BH curve during the FE simulations and developed cutting loss model was derived from the Epstein frame measurements. The Epstein frame test was done on the samples cut from the same mother coil as the manufactured stators and rotor.

\section{Results}

In this section, the fitting parameters obtained for the loss model is presented and the validation of the loss model is discussed. Further, the loss model is applied to a cage induction motor and FE time-stepping analysis is carried out at different load conditions. As the most prominent effect due the cutting was observed in the core losses, the last part deals with the comparative measurements of the EDM cut and laser cut stators.

\section{A. Magnetic measurements on the different width sam- ples}

Epstein frame measurements of different widths samples described in the section II-A were performed. Five different sinusoidal excitation frequencies were considered: $20 \mathrm{~Hz}, 50$ $\mathrm{Hz}, 100 \mathrm{~Hz}, 200 \mathrm{~Hz}$ and, $400 \mathrm{~Hz}$. As a result, single valued magnetization curve in form of a peak value of magnetic flux density $\left(B_{p}\right)$ and the peak value of magnetic field strength $\left(H_{p}\right)$ along with specific core loss density curve in form

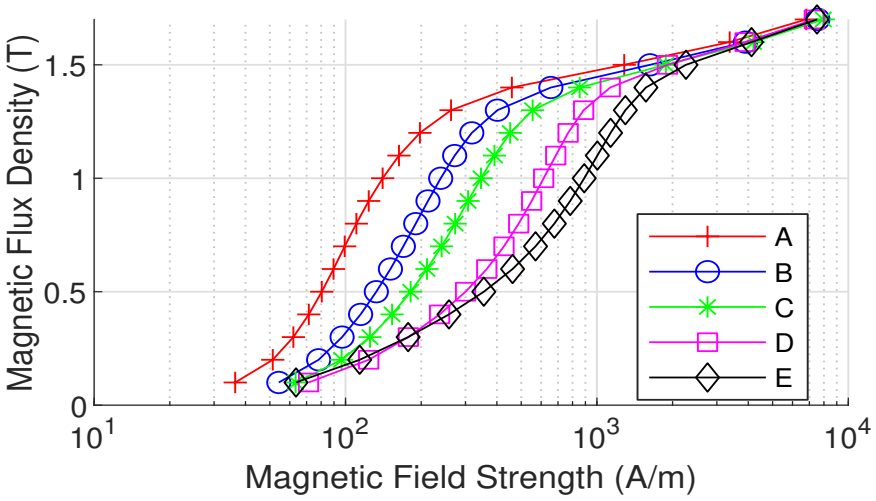

Fig. 4: Measured magnetization curves at $50 \mathrm{~Hz}$ for different sample widths. The detail of samples are provided in Table I.

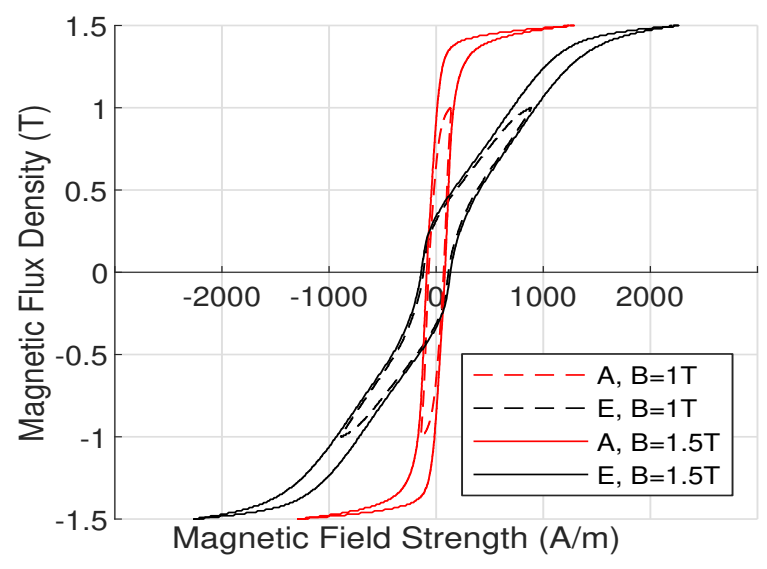

Fig. 5: Measured magnetization loops at $50 \mathrm{~Hz}$.

of loss density $P_{c}$ versus $B_{p}$ were obtained. The effect of cutting on magnetic permeability can be analyzed from Fig. 4 which shows the $B H$ curve at $50 \mathrm{~Hz}$ of different samples. Hysteresis loops of least degraded sample i.e. sample A and most degraded sample i.e sample $\mathrm{E}$ at peak flux magnetic flux densities of $1 \mathrm{~T}$ and $1.5 \mathrm{~T}$ are presented in Fig. 5. Further, the core loss increase due the cutting is presented in terms of core loss density in Figs. $6 \mathrm{a}$ and $6 \mathrm{~b}$, measured at excitation frequencies $50 \mathrm{~Hz}$ and $400 \mathrm{~Hz}$ respectively.

\section{B. Parameter fitting of the loss model}

Under measurements, we have obtained the peak value of average magnetic flux density and average core loss density along the width of a sample. Therefore, the proposed local distributions (1), (4) and (5) need to be averaged in order to compare with the measurements. For the fitting, nonlinear least squares toolbox of MATLAB was used.

In the case of $\mathrm{BH}$ curve fitting, special care needs to be taken for the selection of the data points. Relatively more data points are needed between field strength $30 \mathrm{~A} / \mathrm{m}$ to $1000 \mathrm{~A} / \mathrm{m}$ due to more prominent cutting-effect in this range. In this paper, about $80 \%$ of the field strength data points are selected uniformly in the range $30 \mathrm{~A} / \mathrm{m}$ to $1000 \mathrm{~A} / \mathrm{m}$ whereas remaining $20 \%$ upto $10000 \mathrm{~A} / \mathrm{m}$. The obtained $\Delta \mu$ is presented in Fig. 7. 


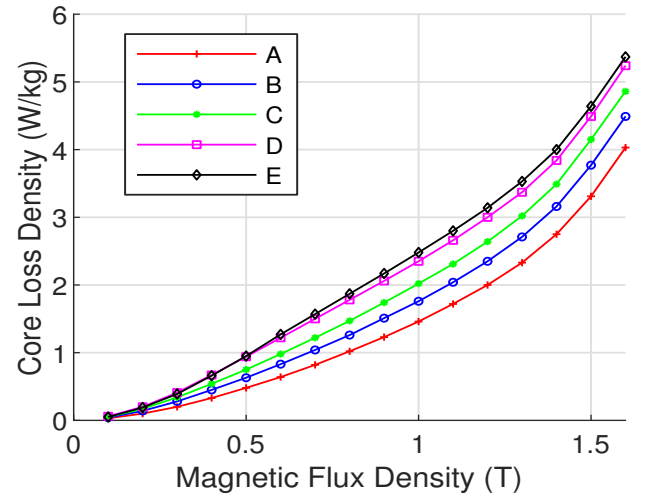

(a)

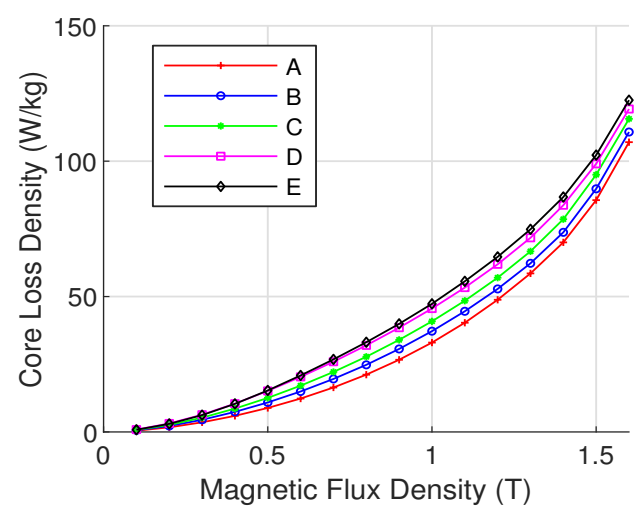

(b)

Fig. 6: Measured core loss curves of different width samples at (a) $50 \mathrm{~Hz} \mathrm{(b)} 400 \mathrm{~Hz}$.

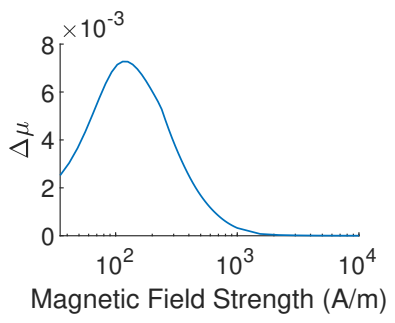

Fig. 7: Fitted parameter $\Delta \mu$. Effect of cutting will be mainly below $1000 \mathrm{~A} / \mathrm{m}$ field strength.

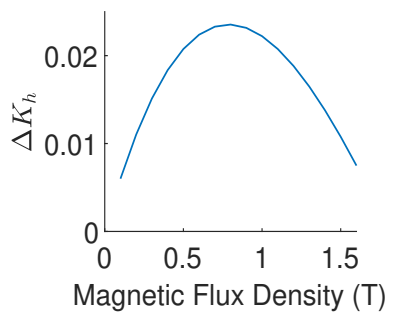

(a)

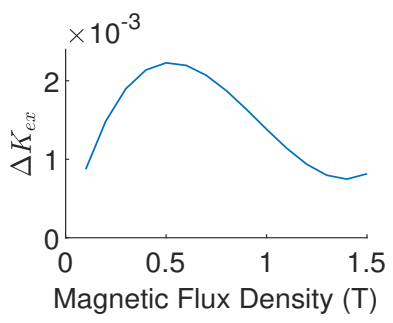

(b)
Fig. 8: Parameter (a) $\Delta K_{h}$ (b) $\Delta K_{e x}$.

Similar to the BH curve data, the average hysteresis $\left(\tilde{K_{h m}}\right)$ and excess $\left(K_{\text {exm }}^{\sim}\right)$ loss coefficients were obtained and fitted with the corresponding calculated hysteresis $\left(\tilde{K_{h c}}\right)$ and excess
TABLE II: Fitting results

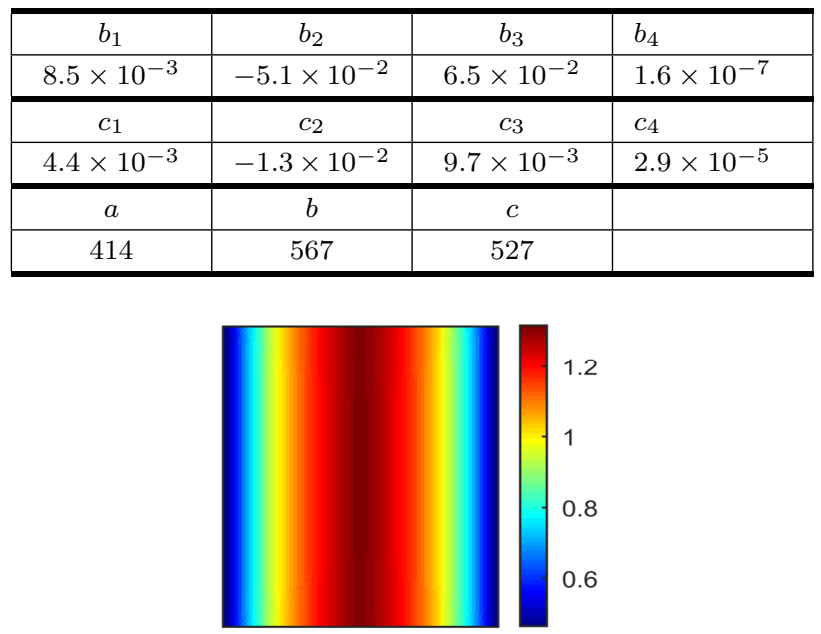

Fig. 9: Magnetic flux density distribution when average flux density of $1 \mathrm{~T}$ was enforced on the sample A. The cutting effect was considered on left and right edges; hence the magnetic flux is concentrated in middle of the sample.

$\left(\tilde{K_{\text {exc }}}\right)$ loss coefficients. The obtained fitting parameters $\Delta K_{h}$ and $\Delta K_{e x}$ are presented in Fig. 8. The corresponding fitting coefficients in SI units are summarized in Table II. The profiles of $\Delta \mu, \Delta K_{h}$ and $\Delta K_{e x}$ show that the effect of cutting reduces towards the magnetic saturation. Based on the obtained fitting parameters $a, b$, and $c$, the damaged region is upto about 5 $\mathrm{mm}$ where the exponential degradation reduces to $10 \%$ of the peak value at the cutting edge. Here, the measurement data points are between $0.1 \mathrm{~T}$ and $1.6 \mathrm{~T}$. As the loss coefficients are dependent on $B$, loss coefficients out of the measured range are kept constant at the respective limits of $B$.

\section{Validation of proposed loss model}

$\mathrm{FE}$ analysis of Epstein frame test setup is performed with the presented loss model. The details of the FE model is described in section II-C. The cut-edge dependent local permeability distribution (1) will be applied. This resulted in a flux density distribution (Fig. 9) which clearly shows the effect of cutting. The core losses in the sample are further computed in a post-processing manner using (3), (4) and (5). Figs 10a and $10 \mathrm{~b}$ represent the calculated and measured core losses at different enforced average magnetic flux densities at different sample widths at $50 \mathrm{~Hz}$ and $400 \mathrm{~Hz}$ excitation frequencies respectively. The calculated core losses match the measured values reasonably. The loss model is generated from the measured flux density range between $0.1 \mathrm{~T}$ to $1.6 \mathrm{~T}$. However, the presented loss model predicts losses with good accuracy in extrapolated region as shown in Fig 10a for enforced flux density of $1.7 \mathrm{~T}$. Other than low enforced flux density of 0.4 $\mathrm{T}$ the relative error is less than $10 \%$ as shown in the Figs 11a and $11 \mathrm{~b}$ for samples $\mathrm{C}$ and $\mathrm{E}$ which are considered degraded. The comparatively high relative error $(\sim 10 \%)$ in sample A was expected, as non-degraded parameters are derived from sample A. However, during FE simulations cutting effect was considered in sample A as well. 


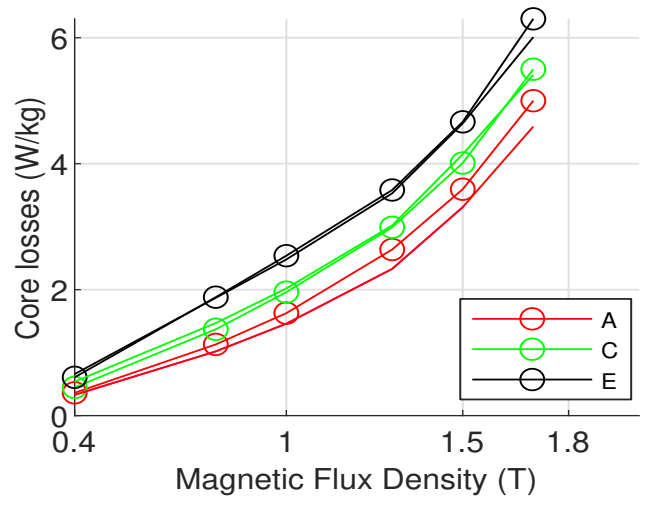

(a)

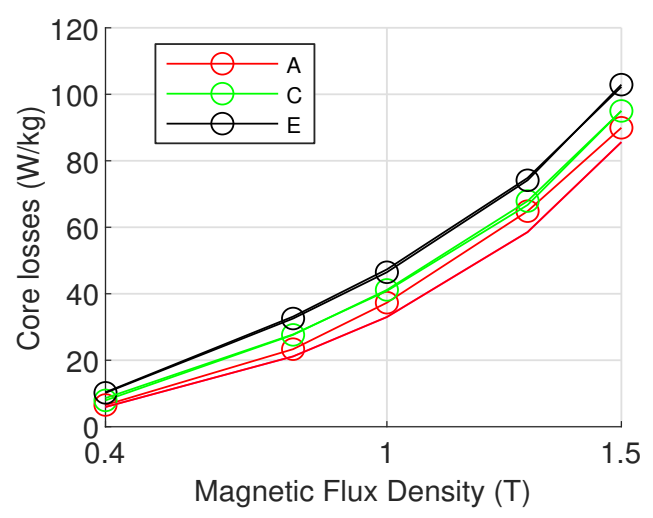

(b)

Fig. 10: Calculated core loss curves of different width samples at (a) $50 \mathrm{~Hz}$ (b) $400 \mathrm{~Hz}$. Calculated and measured values are represented by lines with marker and solid lines respectively.

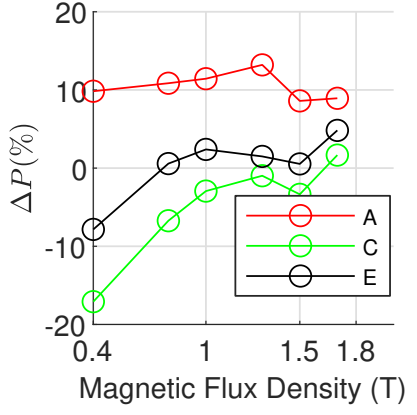

(a)

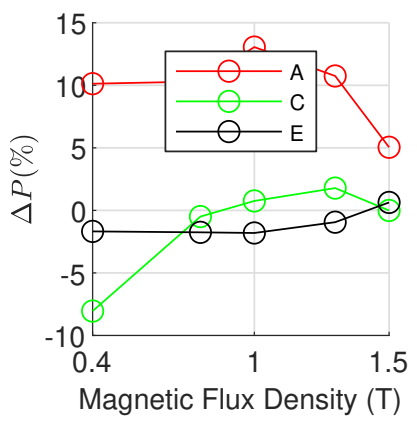

(b)
Fig. 11: Relative error in measured and calculated core losses of different width samples at (a) $50 \mathrm{~Hz}$ (b) $400 \mathrm{~Hz}$.

\section{Cutting effect on machine performance}

Time-stepping finite element analysis of a cage induction machine was performed. The motor data is presented in the appendix section in Table V. The simulation results were obtained by either considering or not the presented permeability and core-loss models. The effect of cutting is quite easily visible in a number of machine parameters. First, as this is a voltage source simulation model, the no load current has increased due to lower permeability of iron near the cut-edges
TABLE III: Cutting effect at no-load

\begin{tabular}{|c|c|c|c|}
\hline & $\begin{array}{c}\text { No load } \\
\text { without } \\
\text { cutting } \\
\text { effect }\end{array}$ & $\begin{array}{c}\text { No load } \\
\text { with } \\
\text { cutting } \\
\text { effect }\end{array}$ & $\begin{array}{c}\text { \% } \\
\text { Difference }\end{array}$ \\
\hline Supply current (A) & 28.5 & 30.2 & 6 \\
\hline Core loss (W) & 331 & 388 & 14 \\
\hline Stator core loss (W) & 270 & 304 & 13 \\
\hline Stator hysteresis loss (W) & 163 & 178 & 9 \\
\hline Stator excess loss (W) & 33 & 49 & 48 \\
\hline
\end{tabular}

TABLE IV: Cutting effect at full-load

\begin{tabular}{|c|c|c|c|}
\hline & $\begin{array}{c}\text { Full load } \\
\text { without } \\
\text { cutting } \\
\text { effect }\end{array}$ & $\begin{array}{c}\text { Full load } \\
\text { with } \\
\text { cutting } \\
\text { effect }\end{array}$ & $\begin{array}{c}\text { \% } \\
\text { Difference }\end{array}$ \\
\hline Supply current (A) & 67.8 & 68.5 & 1 \\
\hline Torque (Nm) & 238 & 239 & 0.4 \\
\hline Core loss (W) & 416 & 482 & 16 \\
\hline Stator core loss (W) & 323 & 370 & 14 \\
\hline Stator hysteresis loss (W) & 172 & 189 & 10 \\
\hline Stator excess loss (W) & 47 & 78 & 66 \\
\hline
\end{tabular}

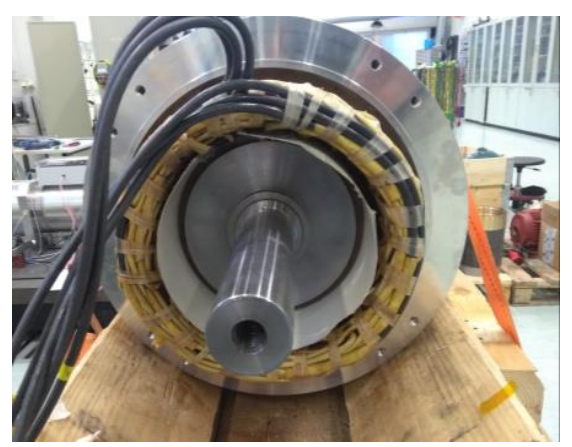

Fig. 12: Blocked rotor setup. Laminated rotor without rotor slots and conductors.

as presented in Table III. The core losses computed at no load and full load, both indicate a clear increase in core-loss of the full machine as presented in Table III and Table IV. The total core-loss has increased by about $14 \%$ due to the cutting effect. The full load current and torque show negligible effect due to the cutting effect.

Additionally, this paper extends the application of computationally efficient time-harmonic based higher order finite element analysis [21] to higher order time-stepping analysis with the cutting effect. The computation time is about 40 seconds for solving the resultant system for 200 time-steps. The finite element mesh contains 1516 third order elements and 6901 nodes. The simulation PC has 16 GB RAM and clock speed of $3.3 \mathrm{GHz}$.

\section{E. Measurement of core losses with mock-up machine}

From the simulation of $37 \mathrm{~kW}$ induction machine, it is clear that the core losses are affected the most as compared to other parameters such as supply current, torque, etc. Therefore this 


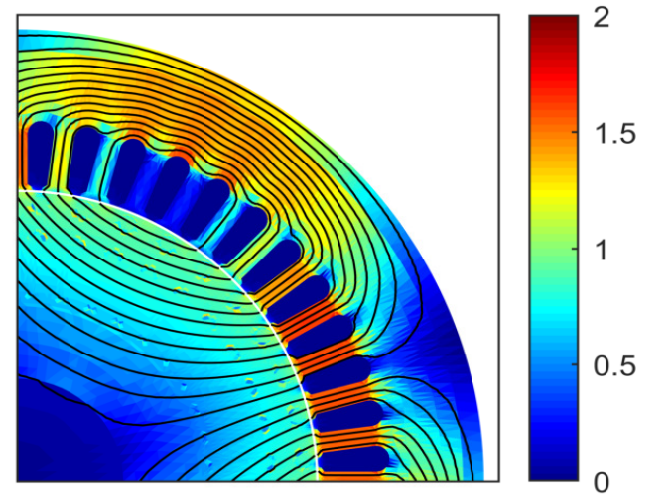

(a)

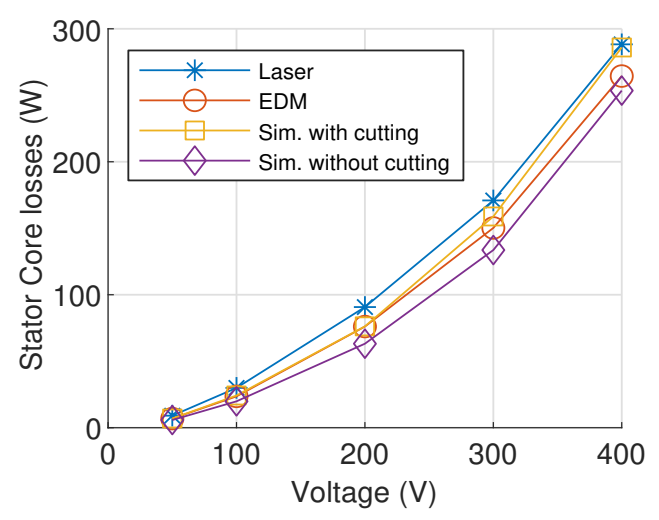

(b)

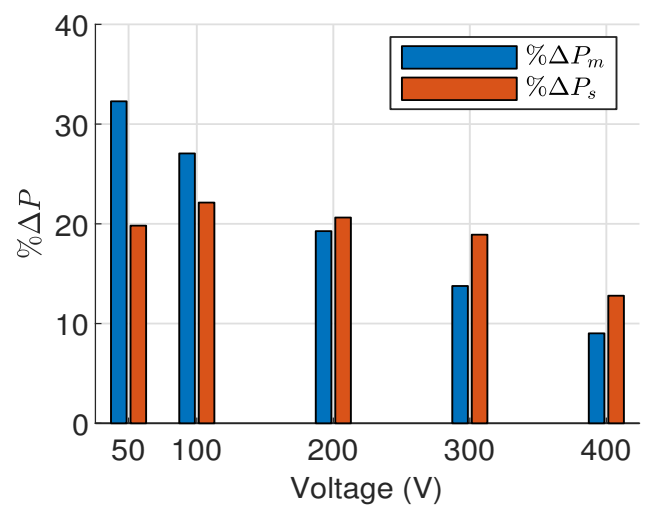

(c)

Fig. 13: (a) Magnetic flux density distribution in laminated blocked rotor (b) Simulated and measured core losses at 50 $\mathrm{Hz}$ and different supply voltages (c) \% Difference in measured $\left(\% \Delta P_{m}\right)$ and simulated $\left(\% \Delta P_{s}\right)$ stator core losses due to cutting at $50 \mathrm{~Hz}$.

section focuses on reliable and accurate measurement of stator core losses and studying the effect of cutting on it.

The blocked rotor mock-up machine setup is presented in the Fig.12. The mock-up machine has identical stator geometry and winding configuration as the simulated $37 \mathrm{~kW}$ induction machine in the previous subsection. However, the cage rotor is replaced with a unsloted laminated rotor having the same outer and inner rotor diameter as presented in Table $\mathrm{V}$. The supply voltages, current and power measurements are recorded by Fluke Norma 4000 power analyzer [29]. The current probe to the power analyzer is connected with Fluke Norma 30 A shunt registers to measure the supply current. From the measurement setup total losses, supply power, supply frequency, supply voltage were noted. As this is a blocked rotor test, the measured total power loss consists of the copper losses and the core losses. Further, four different sinusoidal supply frequencies were considered as $15 \mathrm{~Hz}, 25 \mathrm{~Hz}, 33.33$ $\mathrm{Hz}$, and $50 \mathrm{~Hz}$. The supply at a different frequency is provided by a synchronous generator coupled with a DC motor. The supply voltages are then controlled to have the same voltage to frequency (V/f) ratio. Under this study, V/f ratio of 1, 2, 4, 6, and 8 were considered. At rated supply $(400 \mathrm{~V}, 50 \mathrm{~Hz}$, $\mathrm{V} / \mathrm{f}=8$ ), the simulated flux density distribution of the blocked rotor test is presented in Fig 13a.

The copper losses are calculated from the measured supply current and resistance of the winding. The difference between the total loss and copper loss is then considered as total core loss (stator core loss + rotor core loss). As the rotor is same in both the measurements, rotor core losses can be considered identical at a given operating condition. The simulated rotor core loss is subtracted from the total core loss to arrive at the stator core loss. The effect of harmonics generated due to stator slots and the magnetic saturation is considered while calculating the simulated core losses. Fig. 13b shows the stator core loss of measured laser cut, EDM cut and simulations with and without considering the cutting effect at $50 \mathrm{~Hz}$.

The effect of cutting in terms of difference in the stator core losses is analyzed by measurements and the presented cutting loss model.

- $\Delta P_{m}$ is difference in measured stator core losses between laser cut and EDM cut stators.

- $\Delta P_{s}$ is difference in simulated stator core losses with and without considering the cutting effect.

As shown in Fig. 13c the measured stator core loss increase due to cutting effect was about $9 \%$ at the rated supply (400V, $50 \mathrm{~Hz}$ ). The increase in core losses was in the range of $30 \%$ to $9 \%$ across the different supply voltages at $50 \mathrm{~Hz}$. Moreover, the measurements at different supply frequencies are presented in Fig. 14 in terms of the difference in stator core losses. The simulated results closely follow the measured results which prove the applicability of the presented loss model.

The differences between computed stator losses from simulations without considering cutting effect and measurements of EDM cut stator are about 5\% at rated supply voltage and about $15 \%$ at lower voltages (flux). Similar differences are observed in the laser cut measurements and simulations with cutting effect. The presented differences are considered well within the limits for the core loss measurements. Further, The error in power measurements done by Norma 4000 [29] is under $1 \%$ based on the data manual.

\section{CONCLUSION AND DISCUSSION}

This paper studies the effect of laser cutting in electrical machines. Laser cutting is performed for small scale production of machines in the industry. The presented research work should allow the machine designers to account for the cutting related losses at the design stage. 


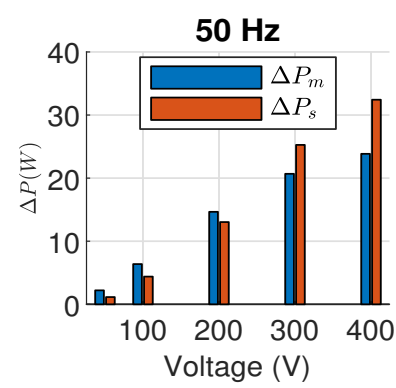

(a)

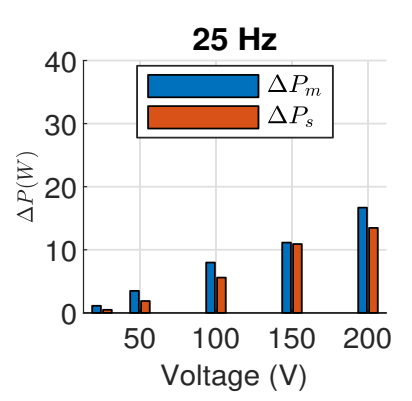

(c)

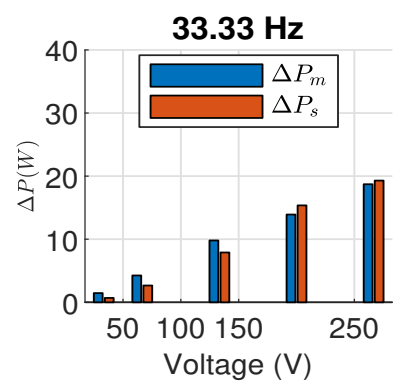

(b)

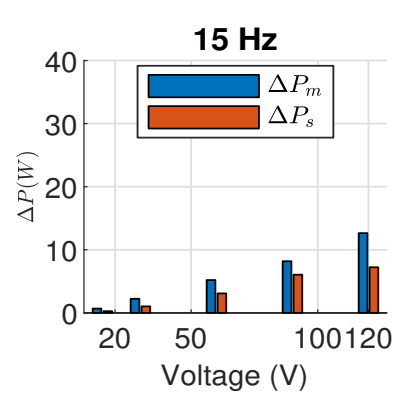

(d)
Fig. 14: Increase in stator core losses due to cutting effect. (a) Supply frequency $50 \mathrm{~Hz}$ (b) Supply frequency $33.33 \mathrm{~Hz}$ (c) Supply frequency $25 \mathrm{~Hz}$ (d) Supply frequency $15 \mathrm{~Hz}$. Voltages are selected to provide same V/f ratio across the measured frequencies.

A cutting model of the electrical steel sheet is proposed, and the parameters are estimated from standard Epstein frame measurements of samples of different widths. The selection of suitable data points for least squares fitting and generation of monotonically increasing $\mathrm{BH}$ curve seems to be major challenges of the cutting model. The computed core losses from the FE simulation of the Epstein frame test setup matches the respective measured values reasonably, hence validates the presented loss model. Indeed, it is difficult to justify the physical basis of the presented local permeability and coreloss distributions. While developing a model for a complex natural phenomenon like cutting, the simplest natural function like exponential that qualitatively matches the phenomenon (cutting effect decays with distance) and reasonably well replicates observations, is a good choice for the time being, until and unless more detailed measurements are performed. Similarly, a cubic polynomial for the effect of cutting on the core loss coefficients is a fair assumption of the underlying physical function.

Further, the effect of cutting was analyzed by time-stepping FE simulation of a typical industrial motor $(37 \mathrm{~kW}$ cage induction motor). The machine performance parameters such as core-losses, supply current and torque was discussed. The major effect was observed in the stator core losses which increased about $14 \%$ due to the cutting effect. The comparative core loss measurements on the EDM cut and laser cut stator with unsloted rotor facilitate the analysis of the cutting effect in the full machine. At rated condition $(400 \mathrm{~V}, 50 \mathrm{~Hz})$ the laser cut stator core losses were $9 \%(24 \mathrm{~W})$ more than the EDM cut stator. The presented cutting loss model follows the measurements results closely over the studied data points.

Finally, the proposed methodology should be suitable for analyzing other cutting methods also and thus be suitable for designing the mass-produced machines. The verification of the proposed method with other cutting methods would be part of the future work.

\section{APPENDIX}

TABLE V: Motor data

\begin{tabular}{|l|l|}
\hline Shaft Power & $37 \mathrm{~kW}$ \\
\hline Voltage & $400 \mathrm{~V}$ \\
\hline Frequency & $50 \mathrm{~Hz}$ \\
\hline Connection & Star \\
\hline Pole pairs & 2 \\
\hline Stator outer diameter & $310 \mathrm{~mm}$ \\
\hline Stator inner diameter & $200 \mathrm{~mm}$ \\
\hline Air gap & $0.8 \mathrm{~mm}$ \\
\hline Number of stator slots & 48 \\
\hline Number of rotor slots & 40 \\
\hline
\end{tabular}

\section{REFERENCES}

[1] K. Bourchas, A. Stening, J. Soulard, A. Broddefalk, M. Lindenmo, M. Dahlen, and F. Gyllensten, "Influence of cutting and welding on magnetic properties of electrical steels," in 2016 XXII International Conference on Electrical Machines (ICEM), pp. 1815-1821, Sep. 2016.

[2] V. Manescu-Paltanea, G. Paltanea, and I. V. Nemoianu, "Influence of edge mechanical stress on the $50 \mathrm{hz}$ magnetic properties of thin electrical steel," in 2017 International Conference on Optimization of Electrical and Electronic Equipment (OPTIM) 2017 Intl Aegean Conference on Electrical Machines and Power Electronics (ACEMP), pp. 450-455, May. 2017.

[3] G. Loisos and A. J. Moses, "Effect of mechanical and nd:yag laser cutting on magnetic flux distribution near the cut edge of non-oriented steels," J. Mater. Process. Technol., vol. 161, no. 1, pp. $151-155,2005$.

[4] F. Ossart, E. Hug, O. Hubert, C. Buvat, and R. Billardon, "Effect of punching on electrical steels: Experimental and numerical coupled analysis," IEEE Trans. Magn., vol. 36, no. 5, pp. 3137-3140, Sep. 2000.

[5] H. Zhao, E. Ferrara, V. M. Paltanea, G. Paltanea, H. Gavrila, and F. Fiorillo, "Effect of punching and water-jet cutting methods on magnetization curve and energy losses of non-oriented magnetic steel sheets," Int. J. Appl. Electrom., vol. 55, no. S1, pp. 69-76, 2017.

[6] H. Liu and J. Lee, "Optimum design of an ie4 line-start synchronous reluctance motor considering manufacturing process loss effect," IEEE Trans. Ind. Electron., vol. 65, no. 4, pp. 3104-3114, Apr. 2018.

[7] F. Martin, U. Aydin, R. Sundaria, P. Rasilo, A. Belahcen, and A. Arkkio, "Effect of punching the electrical sheets on optimal design of a permanent magnet synchronous motor,' IEEE Trans. Magn., vol. 54, no. 3, pp. 1-4, Mar. 2018.

[8] M. Bali and A. Muetze, "Modeling the effect of cutting on the magnetic properties of electrical steel sheets," IEEE Trans. Ind. Electron., vol. 64, no. 3, pp. 2547-2556, Mar. 2017.

[9] N. Boubaker, D. Matt, P. Enrici, F. Nierlich, and G. Durand, "Measurements of iron loss in pmsm stator cores based on cofe and sife lamination sheets and stemmed from different manufacturing processes," IEEE Trans. Magn., vol. 55, no. 1, pp. 1-9, Jan. 2019.

[10] Z. Gmyrek and M. Lefik, "Influence of geometry and assembly processes on the building factor of the stator core of the synchronous reluctance motor," IEEE Trans. Ind. Electron., vol. 64, no. 3, pp. 2443-2450, Mar. 2017.

[11] M. Bali, H. De Gersem, and A. Muetze, "Determination of original nondegraded and fully degraded magnetic characteristics of material subjected to laser cutting," IEEE Trans. Ind. Appl., vol. 53, no. 5, pp. 4242-4251, Sep. 2017. 
[12] T. P. Holopainen, P. Rasilo, and A. Arkkio, "Identification of magnetic properties for cutting edge of electrical steel sheets," IEEE Trans. Ind. Appl., vol. 53, no. 2, pp. 1049-1053, Mar. 2017.

[13] H. Sano, K. Narita, E. Zeze, T. Yamada, U. Kazuki, and K. Akatsu, "A practical approach for electromagnetic analysis with the effect of the residual strain due to manufacturing processes," in 2016 IEEE Energy Conversion Congress and Exposition (ECCE), pp. 1-7, Sep. 2016.

[14] L. Vandenbossche, S. Jacobs, F. Henrotte, and K. Hameyer, "Impact of cut edges in magnetization curves and iron losses in emachines for automotive traction," in Proceedings of 25th World Battery, Hybrid and Fuel Cell Electric Vehicle Symposium \& Exhibition, EVS, Schenzhen, China, Nov. 2010. [Online]. Available: http://134.130.107.200/uploads/bibliotest/2010FHCutedge.pdf

[15] A. Peksoz, S. Erdem, and N. Derebasi, "Mathematical model for cutting effect on magnetic flux distribution near the cut edge of non-oriented electrical steels," Comput. Mater. Sci., vol. 43, no. 4, pp. 1066 - 1068 , 2008.

[16] P. Lazari, K. Atallah, and J. Wang, "Effect of laser cut on the performance of permanent magnet assisted synchronous reluctance machines,' IEEE Trans. Magn., vol. 51, no. 11, pp. 1-4, Nov. 2015.

[17] S. Elfgen, S. Steentjes, S. Bohmer, D. Franck, and K. Hameyer, "Influences of material degradation due to laser cutting on the operating behavior of pmsm using a continuous local material model," IEEE Trans. Ind. Appl., vol. 53, no. 3, pp. 1978-1984, May. 2017.

[18] M. Hofmann, H. Naumoski, U. Herr, and H. Herzog, "Magnetic properties of electrical steel sheets in respect of cutting: Micromagnetic analysis and macromagnetic modeling," IEEE Trans. Magn., vol. 52, no. 2, pp. 1-14, Feb. 2016

[19] R. Siebert, J. Schneider, and E. Beyer, "Laser cutting and mechanical cutting of electrical steels and its effect on the magnetic properties," IEEE Trans. Magn., vol. 50, no. 4, pp. 1-4, Apr. 2014.

[20] R. Sundaria, A. Lehikoinen, A. Hannukainen, A. Arkkio, and A. Belahcen, "Mixed-order finite-element modeling of magnetic material degradation due to cutting," IEEE Trans. Magn., vol. 54, no. 6, pp. 1-8, Jun. 2018.

[21] R. Sundaria, A. Lehikoinen, A. Hannukainen, and A. Arkkio, "Higherorder finite element modeling of material degradation due to cutting," in 2017 IEEE International Electric Machines and Drives Conference (IEMDC), pp. 1-6, May. 2017.

[22] L. Vandenbossche, S. Jacobs, X. Jannot, M. McClelland, J. Saint-Michel, and E. Attrazic, "Iron loss modelling which includes the impact of punching, applied to high-efficiency induction machines," in 2013 3rd International Electric Drives Production Conference (EDPC), pp. 1-10, Oct. 2013.

[23] R. Sundaria, D. G. Nair, A. Lehikoinen, A. Arkkio, and A. Belahcen, "Loss model for the effects of steel cutting in electrical machines," in 2018 XIII International Conference on Electrical Machines (ICEM), pp. 1260-1266, Sep. 2018.

[24] "Solid state fiber laser trumpf trulaser cell 3010." [Online]. Available: https://www.trumpf.com/en_INT/products/machines-systems/ laser-welding-systems/trulaser-cell-3000/

[25] "Epsteing frame measurement setup mpg $100 \mathrm{~d}$ by brockhaus measurements." [Online]. Available: https://brockhaus.com/wp-content/uploads/ Messtechnik/Prospekte/Englisch/Electrical-Steel-Tester-MPG-100.pdf

[26] W. Wilczynski, A. Skopec, B. Szubzda, S. Talik, and W. Lipiec "Aspects of the punching and laser cutting effect on the power losses and magnetic flux density distribution in electrical steel," Dusseldorf, Germany: Stahleisen, 2004., pp. 499-503.

[27] D. M. Ionel, M. Popescu, S. J. Dellinger, T. J. E. Miller, R. J. Heideman, and M. I. McGilp, "On the variation with flux and frequency of the core loss coefficients in electrical machines," IEEE Trans. Ind. Appl., vol. 42 , no. 3, pp. 658-667, May. 2006

[28] A. Arkkio, "Analysis of induction motors based on the numerical solution of the magnetic field and circuit equations," Ph.D. dissertation, Laboratory of Electromechanics, Helsinki Univ. of Tech., Espoo, 1987.

[29] "Fluke norma 4000 power analyzer." [Online]. Available: https: //dam-assets.fluke.com/s3fs-public/norma__omeng0200.pdf

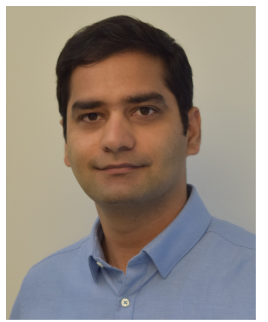

Ravi Sundaria was born in August 1990. He received the B.Tech. degree from Malaviya National Institute of Technology, Jaipur, India, in 2012 and M.Sc. (Tech.) degree from Aalto University, Espoo, Finland, in 2016 with specialization in electrical machines and drives. $\mathrm{He}$ is currently working toward the Ph.D. degree at Aalto University. He worked at Maruti Suzuki India Limited for two years as part of electrical project group. His current research interests include numerical modeling and structural optimization of electrical machines with specific consideration to manufacturing related losses.

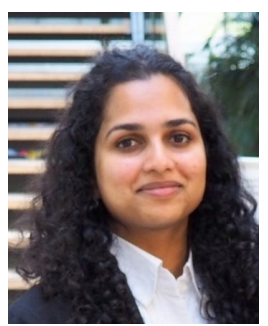

Devi G. Nair was born in Kerala, M.Sc. (Tech.) and D.Sc. (Tech.) degrees in electrical engineering from Aalto University, Finland in 2014 and 2019 respectively. She is currently a R\&D Engineer at $A B B$ Oy, Helsinki, Finland. Her fields of interest include thermal analysis and design of rotating electrical machines.

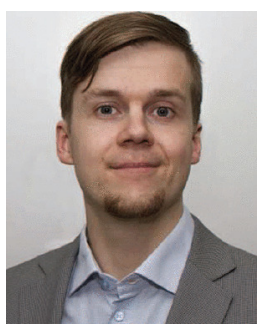

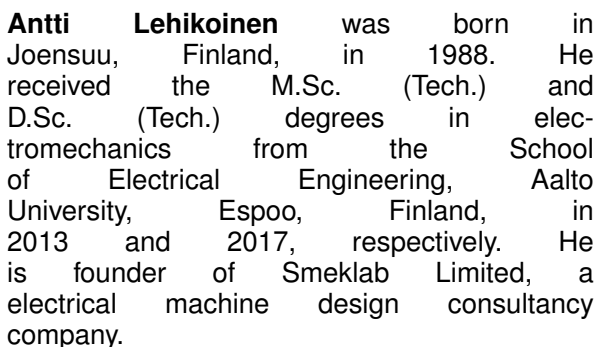

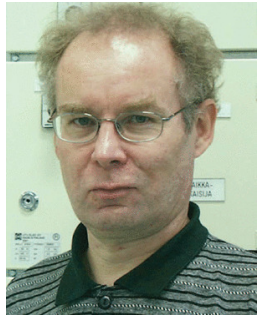

Antero Arkkio was born in Vehkalahti, Finland, in 1955. He received the M.Sc. (Tech.) and D.Sc. (Tech.) degrees from the Helsinki University of Technology, Espoo, Finland, in 1980 and 1988, respectively. $\mathrm{He}$ is currently Emeritus Professor of Electrical Engineering with Aalto University, Espoo. His current research interests include modeling, design, and measurement of electrical machines.

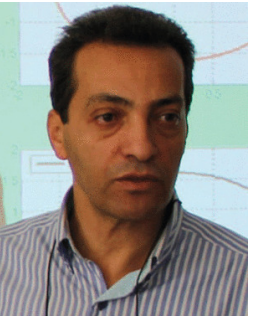

Anouar Belahcen (M'13-SM'15) received the M.Sc. (Tech.) and Doctor (Tech.) degrees from Helsinki University of Technology, Finland, in 1998, and 2004, respectively. He is now Professor of electrical machines at Tallinn University of Technology, Estonia and Professor of Energy and Power at Aalto University, Finland. His research interest are numerical modeling of electrical machines, magnetic materials, coupled magneto-mechanical problems, magnetic forces, magnetostriction, 